\title{
Relações EUA-África: os 10 anos de estabelecimento do Africom (2007-2018)
}

\author{
US-Africa relations: Africom's ten years \\ of establishment (2007-2018)
}

Rev. Bras. Est. Def. v. 6, nº 2, jul./dez. 2019, p. 185-204

DOI: $10.26792 /$ RBED.v6n2.2019.75169

ISSN 2358-3932

\section{GABRIEL PESSIN ADAM \\ NATHALY XAVIER SCHUTZ}

\section{CONSIDERAÇÕES INICIAIS}

As relações entre os Estados Unidos e a África oscilaram bastante ao longo da história. Depois do processo de descolonização dos países africanos, que se iniciou no final da década de 1950, a lógica da Guerra Fria marcou a relação entre o país e o Continente, com os EUA envolvendo-se em conflitos na África para financiar rivais dos grupos comunistas apoiados pela União Soviética. Com o encerramento da era bipolar, a África perde importância na política externa estadunidense.

A inflexão desse processo se dá dentro do redimensionamento da política externa e de defesa dos EUA após os atentados terroristas de 11 de setembro de 2001. Da mesma forma, a crescente presença chinesa no Continente Africano, bem como o novo posicionamento dos países africanos no sistema internacional, conhecido como Renascimento Africano, também marcam o novo momento nas relações EUA-África. É nesse contexto de mudança que se dá a criação do Comando Militar dos Estados Unidos para a África, o Africom, em 2007, foco da presente pesquisa.

As ações dos Estados e suas decisões no Sistema Internacional podem ser analisadas sob várias perspectivas diferentes. Entende-se que, para os

\footnotetext{
Gabriel Pessin Adam - Graduado em Ciências Jurídicas e Sociais pela Pontifícia Universidade Católica do Rio Grande do Sul (1998), mestre em Relações Internacionais pela Universidade Federal do Rio Grande do Sul (2008) e doutor em Ciência Política pela Universidade Federal do Rio Grande do Sul (2013). É professor de Relações Internacionais na ESPM-Sul e na Unisinos.

Nathaly Xavier Schutz - Professora Adjunta de Relações Internacionais na Universidade Federal do Pampa - Campus Santana do Livramento. Graduado em Relações Internacionais pela Universidade Federal do Rio Grande do Sul (2008). Mestre e doutor em Ciência Política pela Universidade Federal do Rio Grande do Sul. Pesquisadora Associada do CEBRAFICA.
} 
fins da presente pesquisa, é necessário um instrumental teórico sistêmico, ou seja, que perceba as mudanças e o comportamento dos Estados do ponto de vista das relações de todo o Sistema Internacional. Isso justifica-se tendo em vista que a criação do Africom e as decisões de política externa dos EUA para a África são pautadas não apenas pela relação do país com o continente, mas sim pela lógica de inserção dos EUA no cenário internacional como um todo.

A estrutura do sistema internacional, assim, é entendida nesse trabalho como o fator determinante no comportamento das potências - nesse caso, dos EUA. Parte-se do pressuposto de que o contexto de crescente ameaça e, principalmente, o ataque sofrido em território nacional, foi o que condicionou a mudança na postura de Washington em relação aos países africanos. Como ressalta Mearsheimer (2001), o comportamento das grandes potências é condicionado pelo ambiente externo, pela estrutura do sistema internacional, e não pelas condições internas.

A alteração na política externa e de defesa estadunidense, assim, com a implementação da Guerra ao Terror, explica-se pelos princípios mais fundamentais da teoria realista: a busca pelo poder como forma de garantir a própria sobrevivência em um ambiente internacional anárquico. As grandes potências dificilmente estão satisfeitas com sua posição no sistema, ao mesmo tempo em que os incentivos para expandir seu poder são constantes. Em um cenário assim estabelecido, a atitude revisionista é permanente, razão pela qual as grandes potências procurarão alterar a balança de poder a seu favor sempre que considerarem que possuem capacidade para tanto e que os custos são baixos. Na medida em que nenhuma potência possui certeza absoluta quanto ao comportamento das demais grandes potências, há uma pressão sistêmica para que elas procurem projetar seus interesses, antes que sejam impedidas por outra potência com interesses semelhantes. Portanto, a posição dos Estados será primordialmente ofensiva (Mearsheimer 2001). A criação do Africom, compreendida como uma iniciativa ambiciosa dos Estados Unidos para a África, pode ser compreendida como um exemplo de atuação ofensiva do país em um continente em que a disputa entre as grandes potências tem se acirrado desde o início do século XXI.

A metodologia empregada na pesquisa foi a histórica-comparativa, adotando-se como técnica a pesquisa de fontes primárias e secundárias. Partindo-se da hipótese de que a criação do Africom, e suas ações derivadas, são fruto da mudança conjuntural na política externa e de defesa dos EUA, o objetivo do trabalho é avaliar a decisão de implementação e o desenvolvimento desse instrumento - o Comando - como o principal recurso de implementação da política de defesa dos EUA para os países africanos. 
O artigo está dividido em três partes além das considerações iniciais e finais. Na primeira parte será feita uma contextualização do cenário internacional na primeira década dos anos 2000, identificando os aspectos conjunturais e as mudanças ocorridas tanto nos EUA quanto na África. Em seguida, será discutida a criação do Comando dos EUA para a África e a reação dos países africanos a esse processo. A última parte é dedicada à análise da evolução da política externa estadunidense para o Continente Africano e o papel que o Africom desempenhou ao longo dos seus primeiros dez anos de existência.

\section{O CONTEXTO INTERNACIONAL NOS ANOS 2000}

Na virada para o século XXI, os Estados Unidos ainda acreditavam serem uma superpotência com uma extensão de poderes tão vasta que não possuiriam limitações relevantes à sua atuação no sistema internacional. A causa dessa ilusão era a concepção de que, com o final da Guerra Fria, não haveria nenhum país ou instituição que pudesse lhe causar um empecilho sério ou, em última instância, refrear suas ações.

$\mathrm{Na}$ ausência de uma superpotência inimiga, os primeiros indícios de um ostensivo papel imperial que seria assumido com orgulho no novo século surgiram quando o Pentágono, em vez de proclamar vitória e decretar desmobilização, começou a tentar novas aptidões, algumas mais tarde abandonadas, outras, pelo contrário,expandidas (Johnson 2007, 30).

O processo de expansão de poder estadunidense possuía relação direta com a concepção de Nova Ordem Mundial propagada pelo Presidente George H. W. Bush (1989-1993), a qual seria uma era de paz, cooperação, baseada no Direito Internacional e nas instituições. De forma aberta, o principal mandatário estadunidense declarou que o seu país seria a liderança necessária na condução do período de transição em curso (Bush 1991). Havia clara tentativa de Washington de moldar o mundo no pós-Guerra Fria, o qual experimentava certa euforia inconsistente com o aprofundamento do processo de globalização.

O cenário idílico previsto por George H. W. Bush, e mantido no nível do discurso pelo Presidente Bill Clinton (1993-2001), nunca se comprovou, fosse pelas crises de partição da Iugoslávia, fosse pelos conflitos no Continente Africano. A violência que assolava países além-mar atingiu os Estados Unidos no dia 11 de setembro de 2011. Os atentados ocorridos no World Trade Center e no Pentágono surpreenderam não apenas a população atingida, mas os membros do sistema internacional como um todo. 
O evento causou modificações tanto na política doméstica do país, com ampliação de medidas de segurança e de restrição de liberdades civis, quanto na condução da política externa. Nessa seara, o objetivo primeiro, manter a condição de principal potência da política mundial, não se alterou (aliás, é uma constante há décadas) - contudo, o discurso foi alterado. A política da Guerra ao Terror (War on Terror) foi lançada como uma verdadeira cruzada a ser enfrentada pelos Estados Unidos, na posição de líder de uma versão muito particular de Ocidente cristão, e o terrorismo internacional passou a ser identificado como a grande ameaça à segurança do país.

The United States of America is fighting a war against terrorists of global reach. The enemy is not a single political regime or person or religion or ideology. The enemy is terrorism - premeditated, politically motivated violence perpetrated against innocents. [...] The struggle against global terrorism is different from any other war in our history. It will be fought on many fronts against a particularly elusive enemy over an extended period of time (United States 2001, 5).

A imprecisão do inimigo genericamente denominado de terrorismo não é gratuita. Quando qualquer grupo, que professa qualquer ideologia ou fé, pode representar uma ameaça, a luta naturalmente se torna global. E, em tese, qualquer Estado pode ser considerado como um patrocinador do terrorismo, ou, ao menos, incapaz de contê-lo em suas fronteiras. A idéia de ataques preventivos complementa essa construção.

While the United States will constantly strive to enlist the support of the international community, we will not hesitate to act alone, if necessary, to exercise our right of self-defense by acting preemptively against such terrorists, to prevent them from doing harm against our people and our country; and denying further sponsorship, support, and sanctuary to terrorists by convincing or compelling States to accept their sovereign responsibilities (United States 2002, 6).

Outros conceitos foram articulados a fim de justificar ações de política externa agressivas, sobretudo no Oriente Médio. Um Estado que possuísse um governo corrompido e instituições que estivessem maculadas a ponto de servir para que o governo subjugasse sua população e a mantivesse na miséria passou a ser chamado de Estado Falido, o que era associado, mesmo que indiretamente, ao terrorismo."Poverty does not make poor people into terrorists and murderers. Yet poverty, weak institutions, and corruption can make weak states vulnerable to terrorists networks and drug cartels within theis borders" (United States 2002).As cidadãs e cidadãos desses países precisariam de apoio da comunidade internacional 
para que seus direitos humanos fossem respeitados, o que demandaria a realização intervenções humanitárias. Somadas a concepção de ataques preventivos e intervenção humanitária, estavam criadas as condições para que os Estados Unidos mantivessem sua imagem por intermédio de um discurso messiânico, enquanto na prática a busca de seus interesses era evidente.

Assim sendo, a mudança causada pelos ataques terroristas de 11 de setembro de 2001 na política de defesa dos EUA é inquestionável:

Although the end of the ColdWar saw the US National Security Strategy steadily evolving as the global strategic environment changed, it is quite clear that the al Qaeda attacks on Washington and New York on 11 September 2001 were a watershed in US foreign policy and defense strategy (Jamieson 2009, 312).

A Guerra ao Terror fez com que as regiões prioritárias da política externa estadunidenseno Governo de George W. Bush (2001-2009) fossem o Oriente Médio e a Ásia Central, o que Brzezinski havia denominado anteriormente deArco das Crises (Brzezinski 1997). Todavia, a luta contra o terrorismo, com todas as suas consequências para os Estados Unidos e para as regiões ou os países porventura mapeados dentro do rol de sítios de grupos terroristas, possuía escopo global, como acima indicado. Logo, a África não ficaria de fora, conforme se verá adiante. Mas antes de indicar como se dava a ligação entre o Continente Africano e a Guerra ao Terror, cabe destacar como a região se encontrava em tal período.

A África, por sua vez, também inaugura um novo momento nas suas relações internacionais, especialmente no posicionamento dos seus Estados nas relações extracontinentais e na construção de uma agenda conjunta comum de todo o Continente. Uma das principais manifestações dessa mudança foi o lançamento da Nova Parceria para o Desenvolvimento da África (NEPAD) em 2001 e a transição da Organização da Unidade Africana (OUA) para União Africana (UA) em 2002.

Como ressalta Visentini (2010 p.12):

Tal tendência deu início a nova fase, na qual os rearranjos da política interafricana talvez estejam produzindo a reafirmação do continente nos assuntos internacionais e na busca de novos paradigmas de desenvolvimento. Na mesma conjuntura da penetração norte-americana no continente no contexto da "Guerra ao Terrorismo", surgiram Estados contestadores, e a China, a Índia e, mesmo, o Brasil se tornaram uma nova presença de peso da África.

Esse novo período do posicionamento africano no sistema internacional ficou conhecido sob o conceito de African Renaissance, o Renascimento 
Africano. O termo Renascimento Africano vai surgir, inicialmente, como uma perspectiva da política externa da África do Sul, durante o governo de Nelson Mandela. ${ }^{1}$. Para Mendonça,

The conception of an African Renaissance that has been occupying the centre of South Africa's African policy, operates in this contradictory context of pessimism/optimism. It recognizes the effects of colonialism, its legacy that led to countries with arbitrary borders, convulsed by ethnic divisions, with unstable political institutions and precarious economies based on the declining production of raw-material and its exportation; but it also recognizes those zones that are start to open themselves to modernization. More than a project, however, the African Renaissance, is an aspiration (Mendonça 2000, 70).

Apesar de surgir dentro do contexto mais restrito da política externa sul-africana, o Renascimento Africano passa a traduzir uma visão de todo o Continente. $\mathrm{O}$ conceito reflete, assim, uma mudança no cenário internacional, que passa a ser mais favorável, ao mesmo tempo que redimensiona a posição da África no Sistema Internacional. Após um período de pessimismo e perda de importância estratégia para as potências ocidentais, durante a década de 1990, a África ganha um novo fôlego a partir do início dos anos 2000.

A demanda crescente por matérias-primas e recursos naturais, bem como a intensificação da Cooperação Sul-Sul entre os países africanos e China, Brasil, Índia e Rússia, proporcionou um novo momento para as economias africanas, que começam a se recuperar após as crises dos anos 1980 e as políticas neoliberais dos anos 1990. Soma-se a isso, a pacificação de alguns conflitos na região, como o encerramento do apartheid na África do Sul e o fim da guerra civil em Angola.

A África, assim, passa a ser vista como uma região mais próspera e mais segura. África do Sul e Nigéria se consolidam como importantes polos de poder regionais e as organizações africanas, como aComunidade Econômica dos Estados da África Ocidental (CEDEAO) e a Comunidade para o Desenvolvimento da África Austral (SADC) passam a ocupar, junto da União Africana (UA), papel de destaque na resolução dos problemas de segurança e de desenvolvimento da África.

Nas palavras de Schraeder (2013, 199):

[...] three trends - the democratization of African foreign policies, rising competition among the Great Powers, and the rising assertiveness of African regional powers - suggests the increased ability of a new generation of African leaders to assume greater control over the international relations of their respective countries. 
Os anos 2000, assim, podem ser compreendidos como uma nova fase não só no contexto global, fruto da própria mudança de política externa e de defesa dos EUA, mas também como um novo período nas relações internacionais africanas. É nessa conjuntura de mudança que se dará a criação do Comando Militar dos EUA para a África.

\section{A EVOLUÇÃO DA POLÍTICA EXTERNA ESTADUNIDENSE PARA A ÁFRICA}

A política externa estadunidense para a África sofreu alterações diretamente relacionadas com os eventos do sistema internacional e com sua posição de potência global. A maior ou menor relevância dos países africanos para Washington eram um indicado de crescimento ou minoração do engajamento efetivo dos Estados Unidos em tal continente. Mas, por outro lado, a concepção de Nova Ordem Mundial e o fato de ser uma grande potência, na época a maior entre seus pares, quiçá a única, lhe gerava uma pressão sistêmica de manter presença e intervir em todos os continentes, a fim de não gerar vácuo de poder (Mearsheimer 2001). A crescente presença chinesa na África desde meados nos anos 1990 igualmente é uma causa para que os Estados Unidos mantivessem o continente em seu horizonte de atuação. Cabe, portanto, destacar as diferentes fases do envolvimento estadunidense com a África.

Ao longo do período da Guerra Fria, o Continente Africano era uma região estratégica para a política externa dos EUA, tendo em vista os enfrentamentos indiretos com a União Soviética, através do financiamento e auxílio a movimentos de libertação que se opunham àqueles de ideologia comunista e/ou que recebiam auxílio de Moscou. Com o encerramento da Guerra Fria e a suposta vitória do capitalismo, a África perde importância no contexto das ações externas estadunidenses.

O baixo envolvimento dos EUA na África a partir dos anos 1990 foi aprofundado após a traumática participação das tropas estadunidenses no conflito da Somália em 1993. Na ocasião, as forças militares dos EUA tiveram baixa de 18 soldados, além de mais de 70 feridos, no episódio que ficou conhecido como Batalha de Mogadíscio (Forest and Crispin 2009). Após esse fato, os EUA retiraram completamente suas tropas da Somália e encerraram sua participação na missão.

Como destacam Bah e Aning (2008), os eventos na Somália levaram a uma modificação não só na política externa de Washington para os países africanos, mas no envolvimento dos EUA em operações de paz como um todo. A partir de então, os EUA passaram a se envolver nas questões africanas apenas quando seus interesses estavam diretamente 
ameaçados. Ainda assim, a preferência era por ações periféricas, como o treinamento de tropas.

O primeiro ponto de inflexão na política africana dos EUA são os atentados terroristas realizados contra duas embaixadas dos EUA na África em 1998. Após os atos terroristas no Quênia e na Tanzânia, Washington reage atacando uma fábrica farmacêutica, no Sudão, acusada de produzir armas químicas para a Al Qaeda (Ploch 2011).

A partir de então, alguns movimentos importantes começam a ser feitos no sentido de redimensionar a política externa estadunidense para a África, ainda que sejam questões mais pontuais. O African Growth and Oportunity Act (2000), que foi lançado durante o governo Clinton e, essencialmente, reduziu barreiras comerciais entre os EUA e os países da África Subsaariana, é um exemplo dessas movimentações de aproximação. Evidentemente, a condição para essas reduções era de que os países não estivessem envolvidos em ações vistas como ameaças à segurança estadunidense.

Alguns anos mais tarde, Washington lança a Global Peace Operations Initiative (2005). Ainda que a iniciativa tratasse de um âmbito de cooperação já existente — o treinamento de tropas para missões de paz —, inova reconhecendo a importância do fortalecimento das organizações regionais nesse âmbito. De acordo com Bah e Aning (2008), essa mudança se explica não só pela maior legitimidade dessas organizações, especialmente depois da reforma da Organização da Unidade Africana para União Africana, mas também pelo protagonismo que tais organizações já vinham desempenhando na resolução das crises securitárias africanas, o que, em parte, foi estimulado pela própria resistência dos países ocidentais em enviar tropas para as operações de paz da ONU.

As graduais alterações nos documentos oficiais do Governo dos EUA no tocante à África são um bom indicativo das mudanças da política externa e de defesa. Na Estratégia Nacional de Segurança de 2002, conforme visto, embora não seja especificamente direcionada ao Estados Africanos, é mencionada preocupação em relação a Estados pobres e com problemas institucionais como possíveis ambientes vulneráveis ao estabelecimento de redes terroristas (Pham 2014). "Indeed, in combating Al Qaeda, the United Stateshas become aware of the numerous ways that organization has already exploited the political and social crisis that have gripped several African states (Dunn 2008, 241). Conforme Bah e Aning (2008), ainda, o documento indicouduas estratégias pontuais para a África: construir e ampliar programas de cooperação bilateral e construir coalizões para enfrentar os problemas de segurança. Já na Estratégia Nacional de Segurança de 2006, a África é identificada como uma área de prioridade, focando na 
necessidade de resolver os problemas, já mencionados, relacionados à fragilidade dos Estados e das instituições democráticas (Ploch 2011).

A Estratégia Nacional de Segurança de 2010, já no governo Obama, marca uma mudança importante no escopo das ações para a África. Segundo Pham (2014), o foco passa a ser as questões mais amplas de desenvolvimento e não apenas aquelas restritas a temas de segurança tradicionais. Soma-se a isso a publicação, em 2012, da Estratégia dos EUA para a África Subsaariana, consagrando quatro pilares de cooperação: fortalecimento das instituições democráticas; estímulo ao crescimento econômico, comércio e investimentos; promoção da paz e segurança; e promoção de oportunidades e desenvolvimento.

No ano de 2015, o governo estadunidense lançou nova Estratégia Nacional de Segurança. No documento foram apontados problemas recorrentes em alguns países africanos, como a corrupção, a ausência de serviços públicos e a repressão à liberdade. Também foram citados conflitos em curso na época, como o do Mali, da República Democrática do Congo,da República Centro-Africana, do Sudão e do Sudão do Sul. Apesar da instabilidade e das limitações apontadas, o tom da análise é otimista, pois menciona os avanços atingidos. É mencionado que muitos países na África estavam fazendo grandes progressos ao fazerem crescer suas economias, melhorar sua governança democrática e o respeito ao Direito, e ao apoiar os direitos humanos e as liberdades básicas. O Continente Africano inclusive é qualificado como o próximo maior centro de crescimento global. Quanto às ações estadunidenses, foram mencionadas o combate à AIDS, à forme e ao vírus Ebola (United States 2015).

A Estratégia Nacional de Segurança de 2018, por fim, enfatiza a relação entre as organizações extremistas violentas e a instabilidade e fragilidade dos Estados africanos. Além disso, em 2018 também foi publicada a Estratégia dos EUA para a África, com foco na cooperação econômica e no fortalecimento de programas de auxílio como forma de fortalecer os Estados africanos.

Ploch (2011) identifica algumas áreas de interesse prioritário dos EUA na África: suprimento de petróleo, segurança marítima, conflitos armados, terrorismo e epidemia de HIV/AIDS. Jamieson (2009) e Pham (2014) compartilham a visão de Ploch e incluem o acesso a rotas marítimas estratégicas e a necessidade de monitorar as ações chinesas na região como aspectos igualmente importantes.

O posicionamento oficial do Governo dos EUA sintetiza seus interesses estratégicos na África em quatro áreas. Além do interesse geral em conter ameaças ao acesso e à influência estadunidense na região, também são preocupações de Washington: o crescente envolvimento de China e Rússia 
na África; a fragilidade dos Estados; e a expansão das organizações extremistas violentas (Usafricom 2019).

\section{A CRIAÇÃO DO AFRICOM}

A criação do Comando Militar dos Estados Unidos para a África foi anunciada pelo então Presidente estadunidense G. W. Bush em fevereiro de 2007 e iniciou suas atividades em outubro do mesmo ano. ${ }^{2}$ A decisão de criar o Africom é uma clara demonstração da importância do Continente Africano para a estratégia de defesa dos EUA.

O Africom foi descrito por membros do Departamento de Defesa dos EUA como um Comando plus. Ele se diferenciaria dos demais Comandos por avançar em questões não militares, o que se traduziria em um grande número de civis de outras pastas governamentais (Ploch 2011). O Comando Africano é concebido, assim, como uma força de escopo mais amplo, que tem como objetivo a construção de um ambiente seguro e estável, o que, por sua vez, deve envolver preocupações com aspectos da sociedade civil e outras questões não militares.

À época da criação do Comando, as declarações de membros do governo estadunidense reforçavam a ideia de que ele se diferenciava dos demais pela sua atuação e objetivos. Jamieson (2009) lembra que o discurso do então Presidente Bush foi cauteloso, enfatizando questões como democracia e desenvolvimento e evitando mencionar a Guerra ao Terror. Theresa Whelan (2007), Subsecretária de Defesa Adjunta para África, destacou a grande presença de membros civis, o apoio às ações diplomáticas e a preocupação com a estabilidade dos Estados africanos.

Para Jamieson $(2009,317)$ "There is a tendency to officially underplay or even deny that Africom was established to protect US supplies of oil or other raw materials, counter China's expansion or fight the war on terror." O posicionamento oficial, assim, era de que a preocupação fundamental e o principal motivador para a criação — do Comando era a construção de uma região segura e desenvolvida, o que seria benéfico não só para os EUA, mas para a África e todo o Sistema Internacional.

A visão mais ampla sobre o escopo de atuação do Comando foi mantida ao longo do tempo. De acordo com a última declaração de situação do Africom para o Senado dos EUA, por exemplo, feita pelo General Thomas D. Waldhauser em fevereiro de 2019, o Comando baseia suas ações em dois princípios fundamentais: a percepção de que, praticamente, nenhum problema africano pode ser resolvido apenas pela força militar; e o fato de que as pressões permanentes sobre as redes terroristas são necessárias para impedir a desestabilização das nações africanas (Usafricom 2019). 
A recepção, por parte dos países africanos, da criação do Africom foi um tanto receosa. Os países membros da Comunidade para o Desenvolvimento da África Austral (SADC), em especial a África do Sul, entenderam a ação dos EUA como uma estratégia para conter a atuação chinesa na África e garantir acesso ao petróleo africano. Segundo Jamieson (2009), as relações entre África do Sul e EUA, embora já tivessem melhorado, estavam estremecidas desde 2003, quando os EUA anunciaram a retirada de auxílio militar a 13 países africanos, incluindo a África do Sul. Sendo assim, o Ministério de Defesa Sul-Africano nem mesmo respondeu a solicitação de encontro com o Comandante representante do Africom, feita pela Embaixada estadunidense.

Além da África do Sul, a Nigéria, maior economia do Continente e com uma força militar expressiva, também foi contrária à criação do Comando. $\mathrm{O}$ país teria, inclusive, articulado movimentações entre a Comunidade Econômica dos Estados da África Ocidental (CEDEAO) e a União Africana para evitar que os Estados Unidos estabelecessem uma base no Golfo da Guiné (Bah and Aning 2008).

A percepção dos líderes africanos, de um modo geral, era de que os Estados Unidos estavam utilizando a justificativa da Guerra ao Terror para disfarçar os seus reais interesses no Continente. O Parlamento PanAfricano, ${ }^{3}$ inclusive, manifestou-se contrariamente à implementação do Comando, recomendando os países africanos a não aceitar solicitações do governo estadunidense de estabelecer o Africom em qualquer parte do território africano (Ploch 2011).

A resistência dos africanos em aceitar a criação do Africom e, por consequência, a expressiva presença militar dos EUA, foi alimentada, também, pela postura estadunidense na condução do processo. Ainda que as declarações oficiais tenham sido cautelosas quanto às intenções de Washington, o governo foi pouco hábil no estabelecimento do diálogo com os países africanos e no uso dos canais diplomáticos. Pham (2014) lembra que essa postura foi agravada por manifestações de militares que minimizaram a importância da criação do Comando, tratando-a como um mero ajuste burocrático na estratégia de defesa estadunidense para a África.

Para Forest e Crispin (2009), a falta de diálogo com os líderes africanos não foi o único problema na criação do Africom. A ausência de planejamento - com o anúncio prematuro da criação - e a falta de preparo para as reações negativas e os problemas iniciais também teriam contribuído para um início pouco positivo do Comando.

O fato de os países africanos não terem uma boa recepção da criação do Comando é justificada em riscos e ameaças plausíveis que a presença militar estadunidense no Continente Africano poderia trazer. Jamieson 
(2009) elenca pelo menos três desses riscos: a probabilidade de uma base militar dos EUA em território africano tornar-se um alvo para ataques terroristas; a possibilidade, ainda que baixa, de algum enfrentamento entre forças estadunidenses e chinesas; e a eventual divisão entre os países da União Africana sobre o posicionamento quanto ao Africom, o que poderia levar a um enfraquecimento da instituição e de outras organizações regionais africanas.

Assim, a implementação do Comando, como pode ser visto, não foi um processo fácil. Além das dificuldades esperadas, considerando a diversidade e complexidade da região africana, os problemas de planejamento e as falhas diplomáticas tornaram a criação do Africom um foco de tensão nas relações entre os EUA e os países africanos.

\section{RESULTADOS DO AFRICOM}

Compreendidas as mudanças na política externa dos EUA para a África, é possível analisar como o Africom se inseriu nesse contexto. Antes de discutir os resultados na implementação do Comando, é importante lembrar que os EUA já desenvolviam outras ações de cooperação em segurança e defesa na África, que, a partir de 2008, passaram a ficar sob o controle do Africom. Pham (2014) destaca: (1) o programa de contraterrorismo Iniciativa Pan-Sahel, lançado em 2002 e ampliado em 2008 para Programa de Contraterrorismo do Pan-Sahara; (2) o Posto de Parceria Africano, iniciativa de treinamento da Marinha Estadunidense criada em 2004; e (3) iniciativas de cooperação bilaterais, com destaque para o Marrocos.

Uma ação pontual a ser destacada é a Força-Tarefa Conjunta ${ }^{4}$ do Chifre da África, lançada em outubro de 2002, e que depois fica sob o comando do Africom. O objetivo da Força-Tarefa era identificar e capturar grupos terroristas que operavam na região. Além das ações militares tradicionais, a Força-Tarefa também atuou no auxílio da Operação de Manutenção da Paz da União Africana na Somália $\left(\right.$ Amisom $\left.^{5}\right)$, oferecendo treinamento militar às tropas e colaborando com organizações não-governamentais no provimento de medicamentos e outras ações humanitárias (Ploch 2011).

É importante ressaltar que o treinamento de forças militares africanas pela Africom figura entre as principais atividades do Comando. Tendo em vista que nenhum país africano é visto como uma possível ameaça aos EUA e que, quanto mais estáveis e seguros esses Estados se tornarem, mais fácil é a atuação estadunidense na região, a melhora das capacidades militares africanas é de grande interesse dos EUA.

Além disso, é relevante lembrar que essa á a única base estadunidense em território africano. De acordo com Pham (2014), ela teve suas funções 
bastante ampliadas desde a sua criação, passando a atuar não só como a base de treinamento, como já foi mencionado, mas também como referência para ações de contraterrorismo na Península Arábica, especialmente no Iêmen.

Além da Força Tarefa Conjunta do Chifre da África, atualmente, outra sete forças estão sob o controle do Africom: o Exército dos EUA para a África $\left(\mathrm{USARAF}^{6}\right.$ ), com base na Itália; as Forças Marinhas dos EUA para Europa e África (MARFOREUR/AF ${ }^{7}$ ), com base na Alemanha; a ForçaTarefa Marítima-Aéreo-Terrestre para Propósitos Especiais e Resposta a Crises na África (SPMAGTF-CR-AF ${ }^{8}$ ), com base na Espanha; as Forças Navais dos EUA para Europa e África $\left(\mathrm{NAVAF}^{9}\right)$; as Forças Aéreas dos EUA para a África $\left(\right.$ Afafrica $^{10}$ ); o Comando de Operações Especiais para a África $\left(\right.$ Socafrica $\left.^{11}\right)$; e a Força de Resposta do Leste Africano $\left(\mathrm{EARF}^{12}\right)$ (Usafricom 2018).

Para além das ações pontuais, o desenvolvimento do Africom ao longo desses dez anos não foi homogêneo. Pode-se afirmar que os primeiros anos do Comando, caracterizados pela sua implementação, adequação e incorporação das ações já existentes, foram bastante turbulentos. As dificuldades iniciais, em grande medida, são frutos das já mencionadas falhas de planejamento.

Na visão de Forest e Crispin (2009), a concepção do Africom foi problemática porque partiu de premissas equivocadas, principalmente uma supervalorização das capacidades internas dos EUA e do trabalho entre as agências e ministérios e uma visão excessivamente otimista sobre a recepção e cooperação dos líderes africanos e de organizações da sociedade civil. Somar-se-ia a isso o lançamento, e consequente início das atividades, prematuro da iniciativa, sem o planejamento necessário, inclusive de questões práticas, como a decisão de onde seria localizado a sede do Comando, por exemplo.

A complexidade do contexto africano também foi um fato de dificuldade no período inicial do Africom. As relações dos EUA com os Estados Africanos, até então, estava muito mais pautada por questões de segurança, especialmente durante o período da Guerra Fria. Havia pouco conhecimento, contudo, sobre a variedade de questões que envolvem os problemas de construção e consolidação do Estado e dos regimes democráticos na África, além das dificuldades de desenvolvimento socioeconômico, ambos fatores intimamente ligados aos aspectos securitários e de defesa.

Após o período inicial de ajustes e de incorporação das ações já existentes, o Africom passou a atuar como um dos principais instrumentos da política externa dos EUA para a África. Naturalmente, ao longo dos anos as agências e os membros dos projetos e do próprio Comando foram 
adquirindo conhecimento sobre o Continente, e as relações com os países africanos também melhoraram.

Ao longo dos anos, diversas ações foram desenvolvidas. É importante lembrar que nem só atividades militares compuseram essas ações. Tella (2016) lembra, por exemplo, a construção de escolas e hospitais na Nigéria e na Libéria e o auxílio para conter as crises de ebola e malária no Continente. Não se deve negligenciar, todavia, as relevantes ações militares que também foram desenvolvidas. Destaca-se a Operação Odyssey Dawn, uma das maiores do Comando, realizada para proteger civis na Líbia, em 2011, de acordo com a Resolução do Conselho de Segurança da ONU (Ploch 2011; Tella 2016).

A resistência dos países africanos em cooperar também foi, gradualmente, sendo vencida. A Nigéria, um dos países mais críticos em relação à criação do Comando, vai, em 2012, solicitar ajuda dos EUA para o combate ao grupo terrorista Boko Haram. Em resposta ao pedido, o Africom atuou controlando as fronteiras do país com Camarões, no intuito de barrar o ingresso ilegal de armas (Tella 2016).

Atualmente, o Comando atua visando cinco objetivos: (1) a colaboração com os parceiros africanos para a segurança regional; (2) a redução das ameaças das organizações extremistas violentas e das organizações criminosas transnacionais a níveis gerenciáveis pelas forças de segurança nacionais; (3) a garantia do acesso e influência dos EUA; (4) a atuação do Africom na preparação do teatro de operações; e (5) a proteção das instalações e do recursos humanos dos EUA (Usafricom 2019).

As ações nas quais o Africom está envolvido, conforme seu último relatório (Usafricom 2019),englobam a totalidade das regiões do Continente. No Leste Africano, destacam-se as ações na Somália, com foco na contenção do al-Shabab e do ISIS, e a disputa de influência com a China no Djibuti. Pequim tem ampliado a cooperação militar com o país, instalando, inclusive, uma base naval muito próxima da base do Africom. Na região do Norte da África, o foco é a instabilidade na Líbia desde a queda de Kadaffi e a tentativa de conter o ISIS.

Já na região do Sahel e dos Grandes Lagos, o foco é a colaboração dos EUA em duas forças conjuntas: a G5 Força Conjunta do Sahel, ${ }^{13}$ com atividades de contraterrorismo; e a Força Conjunta Multinacional, ${ }^{14}$ principal ação para contenção do Boko Haram e do ISIS. É importante destacar a grande ampliação na cooperação com a Nigéria, que havia sido um dos Estados mais críticos à instalação do Africom. No Golfo da Guiné e na África Central, além da cooperação com forças navais para combater as ações de pirataria, a presença russa na África Central é uma preocupação de Washington. 
Por fim, a África Austral é a região mais estável e a que menos sofre com ações de grupos terroristas nos seus territórios. Por consequência, é onde há menos envolvimento dos EUA, que se concentra em cooperação e treinamento de forças de paz e alguns acordos bilaterais, como com a África do Sul.

O Comando Militar dos EUA para a África, assim, desempenha, atualmente, papel central nas relações entre os EUA e a África. É a principal forma de cooperação em defesa e segurança entre o país e o Continente, além de servir para ações pontuais com o intuito de defender os interesses estadunidenses na região.

\section{CONSIDERAÇÕES FINAIS}

O presente artigo teve como foco analisar os 10 primeiros anos de existência do Africom. Antes de centrar o foco na iniciativa estadunidense propriamente dita, foi apresentada contextualização do cenário internacional desde o final da Guerra Fria até o final da primeira década do século XXI. Foi possível observar a concepção que os Estados Unidos possuem acerca do cenário global em geral e da África em especifico, bem como quais foram suas estratégias de atuação nesta e naquele. A compreensão dos resultados do Africom não seria possível sem que os eventos da própria África fossem abordados, o que se fez ao contextualizar o Renascimento Africano.

As diferentes fases da política externa dos Estados Unidos para o Continente Africano puderam ser visualizadas tanto pela reconstrução de fatos relevantes desta atuação quanto pelos documentos oficiais publicados por Washington, sem esquecer a retomada das iniciativas militares implementadas. Essas prepararam o terreno para o Africom, o mais ambicioso e abrangente projeto estadunidense para a África.

Como se pode depreender a partir dos temas tratados, os atos desempenhados pelos Estados Unidos na África são causados pela comunhão dos seguintes fatores: a pressão sistêmica que os Estados Unidos sofrem por serem uma grande potência, suas concepções variadas sobre o que a África representa no contexto internacional, o incontestável ganho de relevância que os países africanos experimentaram nas duas últimas décadas, para além da visão de Washington sobre tais fatos, os interesses sistêmicos e regionais dos Estados Unidos, como esses concebem a crescente presença de outras potências consideradas como rivais na busca de aumentar influência na África e as dinâmicas dos próprios países e regiões africanas. Todos estes fatores se combinam continuamente, logo precisaram ser explorados em conjunto para que se atingisse o objetivo de refletir sobre os resultados do Africom. 
Conforme visto, o Africom possui uma natureza mista, pois, além de seu caráter securitário, ele igualmente detém um aspecto humanitário, tendo em vista a ajuda que os Estados Unidos fornecem, via Africom e outras iniciativas, para debelar alguns dos problemas sociais de países africanos, sobretudo no campo da saúde. Do ponto de vista de estabilização do Continente Africano, que se relaciona com o caráter de segurança da iniciativa, não é possível afirmar que a inciativa tem sido bem sucedida. De acordo com o próprio relatório de 2019 do Africom, há regiões da África que continuam com elevado grau de instabilidade, especialmente o Norte do continente e o Sahel. A atuação de grupos fundamentalistas nessas localidades, com destaque para as vertentes e as afiliadas da Al Qaeda. Em outras palavras, as dinâmicas africanas por vezes são por demais complexas para que os Estados Unidos consigam entendê-las por completo, que dirá controlá-las. Se, por um lado, houve avanços neste campo, estesainda não correspondem às intenções originárias do Africom.

No campo humanitário, o Africom parece obter resultados mais palpáveis. Ainda que as dificuldades sociais como a fome as epidemias de doenças, frutos dos conflitos africanos e da herança não debelada do colonialismo europeu, persistam em vários países, a África tem experimentado avanços nos últimos anos. Por certo, não se pode creditar somente ao Africom tais melhorias, pois agências da ONU e determinados governos locais igualmente detêm sua porção de crédito. Contudo, a iniciativa estadunidense tem alguma parcela no aumento de uma rede social de apoio às populações africanas.

O Africom, como principal canal de atuação dos Estados Unidos na África, também se relaciona com uma perspectiva geopolítica. Como acentuado pela Doutrina de Segurança Nacional de 2015, Washington considera a África como a próxima região de crescimento intensivo do sistema internacional, sucedendo a Ásia. Além de justificar uma presença constante no Continente Africano, sob o ponto de vista do realismo ofensivo, tal fato indica que quanto menos outras grandes potências atuarem neste, maiores serão os ganhos estratégicos estadunidenses. Desde a criação do Africom, a China não somente permaneceu com forte presença na África como tem dotado posturas qualitativamente inéditas, como a citada instalação de uma base militar no Djibuti e a inclusão da África na vertente marítima da Iniciativa One Belt, One Road. Rússia e Índia igualmente têm procurado estreitar os contatos com os países africanos, o que consequentemente torna a primazia desejada pelos Estados Unidos mais distante.

As perspectivas para os próximos anos do Africom dependerão de uma série de fatores que não estão exclusivamente nas mãos dos Estados Unidos, o que geralmente lhes causa certo desconforto, e confronta a rea- 
lidade dos primeiros anos após o final da Guerra Fria. A política externa cada vez mais assertiva da China para o mundo inteiro, e para a África em especial, é um desafio crescente para os projetos estadunidenses. $\mathrm{Na}$ medida em que não há sinal de que haja um refreamento por parte de Pequim, os Estados Unidos precisarão aprender a conviver com uma rival cada vez mais presente e poderosa no Continente Africano. Como Washington reagirá a tal cenário poderá prejudicar ainda mais o quadro de instabilidade de algumas regiões da África. Do ponto de vista dos países africanos, a manutenção do caráter humanitário do Africom e a atuação de outras potências em seu continente pode aumentar seu poder de barganha, o que, se bem utilizado, sedimentará e aprofundará o saudado Renascimento Africano.

\section{REFERÊNCIAS}

Bah, A Sarjoh, and Kwesi Aning. 2008. "US Peace Operations Policy in Africa: From ACRI to Africom". International Peacekeeping15, no.1.https://doi. org/10.1080/13533310701879969

Brzezinski, Zbgniew. 1997. The Grand Chessboard. New York: Basic Books.

Bush, George H. W. 1991. Address Before a Joint Session of the Congress on the State of the Union. Washington. http://www.presidency.ucsb.edu/ws/?pid=19253.

Dunn, Kevin. 2008. "Sub-Saharan Africa". In From Superpower to Besieged Global Power: Restoring World Order after the Failure of the Bush Doctrine, edited by Edward A. Kolodziev and Roger E. Kanet. Athens: The University of Georgia Press.

Forest, James J. F., and Rebeca Crispin. 2009. "Africom: Troubled Infance, Promissing Future". Contemporary Security Policy 30, no.1. https:// doi.org/ $10.1080 / 13523260902759753$.

Jamieson, Capitan (SAN) D. G. 2009. "Africom: a threat or an opportunity for African security?" South African Journal of International Affairs 16, no. 3.https:// doi.org/10.1080/10220460903495215.

Johnson, Chalmers. 2007. As Aflições do Império: Militarismo, Operações Secretas e o Fim da República. Sao Paulo: Editora Record.

Mearsheimer, John J. 2001. The Tragedy of Great Power Politics. New York: W. W. Norton \& Company.

Mendonça, Hélio Magalhães de. 2000. "South African Foreign Policy 1945-1999". In: Brazilian views on South African foreign policy, edited by Samuel Pinheiro Guimarães. 11-90. Brasília: Funag. 
Pham, Peter J. 2014. "The Development of the United States Africa Command and its Role in America's Africa Policy under George W. Bush and Barack Obama". Journal of the Middle East and Africa 5, no. 3. https://doi.org/10.1080/2152084 4.2014 .980192 .

Ploch, Lauren. 2011. Africa Command: U.S Strategic Interests and the Role of the U.S. Military in Africa. Congressional Research Service Report for Congress.

Schraeder, Peter J. 2013. "African International Relations". In Understanding Contemporary Africa, edited by April A. Gordon and Donald L. Gordon. London: Lynne Rienner Publishers, 2013.

Tella, Oluwaseun. 2016. "Africom: hard or soft power initiative?" African Security Review25, no.4. https://doi.org/10.1080/10246029.2016.1225588.

United States. 2001. U.S. National Security Strategy: Strengthen Alliances to Defeat Global Terrorism and Work to Prevent Attacks Against Us and Our Friends. Washington, The National Cathedral.

2002. The National Security Strategy of the United States of America. Washington, White House.

2015. The National Security Strategy of the United States of America. Washington, White House.

United States African Command (Usafricom). 2018. United States African Command: The First Ten Years. Stuttgart, Headquarters United States African Command.

2019. Statement of General Thomas D. Waldhauser, United States Marine Corps Commander United States Africa Command before the Senate Committee on Armed Services.

Visentini, Paulo G. Fagundes. 2010. A África Moderna: um continente em mudança (1960-2010). Porto Alegre: Leitura XXI.

Waltz, Kenneth N. 2002. Teoria das Relações Internacionais. Lisboa: Gradiva.

Whelan, Theresa. 2017. Why Africom? An American Perspective. Pretoria, Institute for Security Studies, Situation Report. 


\section{NOTAS}

1. A primeira vez que o termo é utilizado é em um discurso de Thabo Mbeki, então vice-Presidente da África Sul, na Universidade das Nações Unidas, em 1998.

2. O Africom inicia as atividades como um sub-comando dentro do Comando Europeu e passa a atuar de maneira independente em fevereiro de 2018 (Ploch 2011).

3. Órgão da União Africana.

4. Combined Joind Task Force

5. African Union Peacekeeping Mission in Somalia.

6. US Army Africa.

7. U.S. Marine Forces Europe and Africa.

8. The Special Purpose Marine Air-Ground Task Force - Crisis Response - Africa.

9. U.S. Naval Forces Europe and Africa.

10. U.S. Air Forces Africa.

11. Special Operations Command Africa.

12. The East African Response Force.

13. A força é composta por Burkina Faso, Chade, Mali, Mauritânia e Níger. 14. A força é composta por Benin, Camarões, Chade, Níger e Nigéria. 


\section{RELAÇÕES EUA-ÁFRICA:}

OS 10 ANOS DE ESTABELECIMENTO DO AFRICOM (2007-2018)

\section{RESUMO}

Os Estados Unidos criaram o Africom em 2007, modificando sua atuação na África. Utilizando a perspectiva do realismo estrutural, o objetivo do artigo é identificar os objetivos dos Estados Unidos com o Africom, e analisar as ações do Comando até 2018. Entende-se que as metas de Washington foram parcialmente atingidas.

Palavras-chave: África; Africom; Estados Unidos; Segurança.

\section{ABSTRACT}

The United States created Africom in 2007, changing its operations in Africa. Using the perspective of structural realism, the objective of the article is to identify the United States' objectives with Africom, and to analyze the Command's actions until 2018. It is understood that Washington's goals have been partially achieved.

Keywords: Africa; Africom; Unites States; Security. 